\title{
Academic/Scientific Impact of a Publication
}

Miguel Abambres

Recognition of the importance of the publication for the state of art and/or the development of some research work. That recognition is measured, in its simplest and most traditional way, by the total number of citations that publication gets from the literature until a specific date. For the interested reader, although unfortunately (as far as I am concerned) it's not yet implemented by academic/scientific platforms, several metrics are proposed in the literature (check Abambres and Arab $2016^{[1]}$ ) to credit each individual co-author of a publication, i.e. to compute his/her \% of the total number of citations attributed to that publication.

As in 'Bye Bye Peer-Reviewed Publishing' [2].

\section{References}

1. ${ }^{\wedge}$ https://Www.researchgate.net/publication/309121652 Citations Authorship Order - Scientific Performance

2. ^ https://www.researchgate.net/publication/332626809 Bye Bye PeerReviewed Publishing undefined 